\title{
RESULTADOS OBTENIDOS \\ EN LA CONSTRUCCIÓN \\ DE UNA «NUEVA ARQUEOLOGÍA» \\ DEL PALEOLÍTICO GALLEGO
}

\author{
Ma DEL MAR LÓPEZ CORDEIRO
}

\begin{abstract}
Resumen
Los trabajos arqueológicos desarrollados dentro del Laboratorio de Arqueología del Instituto de Estudios Gallegos Padre Sarmiento (CSIC/ Xunta de Galicia) entre los años 1996 y 2001, permitieron poner en marcha un proyecto de investigación en paleolítico a largo plazo que presenta una doble orientación científica y patrimonial. Científica porque pretende generar conocimiento sobre los usos del suelo y modos de vida de las sociedades de cazadoresrecolectores. Patrimonial porque el objetivo úl-

timo sería el diseño de un modelo de gestión integral que permita una adecuada protección, intervención, evaluación y difusión del patrimonio paleolítico. Los trabajos de Evaluación y Corrección de Impacto Arqueológico realizados por el Laboratorio dentro del marco de diversas obras públicas, han servido como pretexto y contexto para ensayar metodologías encaminadas a la construcción de lo que podríamos denominar una «nueva arqueología» del paleolítico con base en la arqueología del paisaje.
\end{abstract}

\section{Palabras Clave}

Paleolítico inferior y medio. Paleolítico superior. paisaje. Arqueología espacial. Evaluación y Epipaleolítico. Industria lítica. Arqueología del Corrección de Impacto Arqueológico. 


\section{INTRODUCCIÓN'}

El Programa de Investigación en Paleolítico (PIPA) diseñado desde el Laboratorio de Arqueología tiene como objetivo último el diseño de una propuesta integral de gestión del patrimonio paleolítico con una doble orientación, científica y patrimonial. Cientifica porque pretende generar conocimiento sobre los modos de vida de las sociedades de cazadores-recolectores del paleolítico gallego. Patrimonial porque este conocimiento permitirá una adecuada intervención, protección, conservación y difusión de ese patrimonio.

Para comprender la orientación de nuestros trabajos creemos conveniente estructurar esta charla en tres bloques. En el primero indagaremos las bases de partida de nuestra investigación a través del análisis de la problemática de los estudios de paleolítico generados con anterioridad a nuestros trabajos. Este análisis nos permitirá ver cuáles son las necesidades para diseñar una «nueva arqueología» del paleolítico y la viabilidad de la arqueología del paisaje como línea de trabajo. Finalmente expondremos un resumen de los resultados de los estudios realizados hasta el momento que se han centrado en dos áreas geográficas: el Miño Ourensán y la sierra de Xistral.

\section{PROBLEMÁTICA Y OBJETIVOS DEL PIPA}

La revisión bibliográfica de los estudios del paleolítico gallego nos ha permitido comprobar como hasta época relativamente reciente la imagen que se ha tenido del paleolítico del NO era la de un período arcaico y precario, cuyo estudio podría carecer de significado ante la imposibilidad de establecer una secuencia cronológicocultural completa al modo de las que se han venido construyendo en el resto de Europa, especialmente en la Europa meridional. Los extremos que caracterizan a la problemática del paleolítico gallego y responsables de que la investigación haya avanzado poco en los últimos treinta años se pueden concretar en los siguientes puntos:

\footnotetext{
${ }^{1}$ Una exposición más detallada de los contenidos tratados en este texto, se encuentra en el artículo «La prospección en el paleolítico: aplicaciones en el registro paleolítico gallego» de la Serie de Arqueología Espacial del Seminario de Arqueología y Etnología Turolense, actualmente en prensa.
}

Cuadernos de Estudios Gallegos, Tomo LI, Fascículo 117, Santiago 2004. (Págs. 133 - 151) 


\section{PROBLEMÁTICA}

- Precariedad de programas de investigación de largo alcance y trabajos sistemáticos.

- Deficiencia de estudios sobre el cuaternario.

- Ausencia de prospecciones planificadas.

- Bajo número de yacimientos, especialmente para los períodos más antiguos.

- Elevado número de hallazgos, pero constituidos por escaso número de piezas, comúnmente fuera de contexto.

- Alta vulnerabilidad de los yacimientos.

- Deficiencia de asentamientos o yacimientos en posición primaria.

- Gran extensión de los yacimientos.

- Complejidad de las industrias líticas.

Los problemas enumerados en el cuadro anterior han sido abordados de forma más o menos explícita por la bibliografía tradicional, y sin duda han contribuido en gran medida a que la investigación en paleolítico haya estado en un permanente estado embrionario. Sin embargo, a nuestro entender, la razón de que la investigación en paleolítico apenas haya avanzado se debe a una inadecuada interpretación del registro que se concreta en dos puntos:

- Tratar los yacimientos como entidades aisladas en el paisaje.

- Tratar los yacimientos como si fuesen verdaderos asentamientos.

La selección de la arqueología del paisaje como alternativa a los enfoques tradicionales, se sustenta en la necesidad de disponer de una línea de trabajo que cumpla tres requisitos básicos:

1. que sin obviar la dimensión temporal prime la dimensión espacial.

2. que considere el yacimiento como una entidad integrada en el entorno que la comprende.

3. que estudie los procesos postdeposicionales que han afectado a las industrias después de su abandono.

A estas tres premisas se unen los objetivos básicos de nuestro programa de investigación que se pueden concretar en los siguientes puntos:

\section{OBJETIVOS}

- Delimitar áreas de ocupación y/o áreas de actividad prehistóricas. 
- Revisar áreas o yacimientos conocidos por la bibliografía tradicional y trabajos arqueológicos anteriores.

- Establecer patrones de asentamiento y analizar su evolución a lo largo del paleolítico.

- Determinar la existencia y/o conservación de yacimientos in situ o en posición primaria, sobre todo para los yacimientos de época paleolítica.

- Reconstruir el ambiente en el que vivieron las sociedades que elaboraron los artefactos.

- Comprender las condiciones de formación de los depósitos, atendiendo al estudio de los procesos deposicionales y postdeposicionales que hayan afectado al material arqueológico.

- Realizar un estudio exhaustivo de una serie de yacimientos ubicados en dos zonas clásicas de los estudios del paleolítico con el fin de considerar la posible extrapolación a otras zonas y yacimientos gallegos.

- Establecer los criterios para llevar a cabo una valoración arqueológica de estos yacimientos y/o áreas.

- Derivar las consecuencias de carácter oportunas con el fin de contribuir al establecimiento de criterios de gestión, protección e intervención del patrimonio paleolítico.

\section{PROGRAMA DE TRABAJO}

El Programa de Investigación desarrollado se ha articulado en cuatro planes de trabajo:

\begin{tabular}{ll}
\multicolumn{2}{c}{ Programa de Investigación en Paleolítico (1996-2001) } \\
\hline Plan de Formación & $\begin{array}{l}\text { Cursos y seminarios } \\
\text { Campañas de verano }\end{array}$ \\
Plan de Intervención & Evaluación y Corrección de Impacto Arqueológico en OO.PP. \\
& Campañas de prospección y excavación \\
Plan de Gestión y Análisis & Proyectos dentro del PIPA \\
de Industrias líticas & Otros \\
Plan de Revalorización & Publicaciones \\
& Diseño de rutas, etc. \\
\hline
\end{tabular}

Cuadernos de Estudios Gallegos, Tomo LI, Fascículo 117, Santiago 2004. (Págs. 133 - 151) 


\section{ESTRATEGIA DE TRABAJO}

Los problemas y objetivos expuestos en los apartados anteriores nos han llevado al diseño de una estrategia de trabajo que reúne dos condiciones básicas: adoptar una perspectiva interdisciplinar, que unifique observaciones arqueológicas y geomorfológicas-edafológicas, e integral, que aplique esta observación no sólo al yacimiento sino también al entorno que lo comprende. Teniendo en cuenta estas dos premisas las herramientas de trabajo utilizadas son la prospección y la excavación.

Hemos utilizado la prospección en sus tres modalidades de extensiva, intensiva y cobertura total. La prospección extensiva ha sido utilizada puntualmente para seleccionar áreas donde posteriormente se han intensificado los trabajos. La prospección de cobertura total sólo ha podido ser empleada en aquellos sectores donde el desbroce ha permitido la inspección integral del terreno (seguimientos en obras públicas). En el caso de obras de trazado lineal en las que se contaba con un registro arqueológico netamente continuo desde un punto de vista espacial, se ha procedido al cuadriculado previo del terreno para facilitar las actividades de registro que a continuación se detallan. La prospección de cobertura total y la prospección superficial intensiva han incluido la realización de las siguientes actividades para alcanzar una caracterización más exhaustiva de los hallazgos:

- Recogida sistemática de material lítico.

- Inspección y limpieza exhaustivos de perfiles visibles: descriptivas detalladas de los niveles estratigráficos con identificación y diagnóstico de nivel/es arqueológico/s. Identificación de facies en sentido vertical y horizontal para facilitar la reconstrucción morfosedimentaria de las zonas objeto de trabajo.

- Registro escrito y gráfico de aquellas entidades estrictamente arqueológicas, es decir, aquellas en las que la acción antrópica está constatada (tales como el registro de conjuntos de material); y potenciales, puntos que por sus condiciones de emplazamiento, visibilidad, etc., son susceptibles de haber sido aprovechados por el ser humano pero en las que aún no contamos con evidencias de dicha manipulación.

- Toma de muestras en aquellos puntos que se consideren de interés tanto para el conocimiento arqueológico de la zona como para la reconstrucción paleoambiental del espacio trabajado.

Para aquellos escenarios en los que la prospección resulta insuficiente para una correcta caracterización, se utiliza la excavación en tres modalidades bási- 
cas: (1) zanjas valorativas: excavadas con medios manuales o mecánicos, útiles para definir los límites de las áreas de dispersión de material y para la identificación de la existencia o conservación de niveles arqueológicos; (2) calicatas de sondeo: generalmente de $60 \times 60 \mathrm{~cm}$, empleadas para verificar la presencia humana en espacios fácilmente acotables en el espacio, tales como abrigos rocosos; (3) excavación de sondeos manuales con metodología de excavación en área que incluye el registro tridimensional de los materiales arqueológicos. La ficha de registro utilizada contempla no sólo el estudio de las orientaciones y buzamientos de las piezas sino también el registro de determinados caracteres geográficos útiles para la caracterización de los depósitos. Para que ésta sea más exhaustiva se procede además al registro de los elementos naturales que acompañan a la industria lítica tallada.

Para alcanzar una mejor comprensión, sistematización e interpretación de las áreas de investigación hemos utilizado la localidad, una unidad de registro que permite dar coherencia a una información que en muchos casos ha sido recopilada de forma aislada y amoldada a ritmos de trabajo discontinuos. Esta unidad permite organizar las áreas objeto de trabajo en diferentes sectores atendiendo a diversos criterios establecidos de antemano, tales como la existencia de concentraciones significativas de material, existencia o conservación de niveles arqueológicos, pertenencia a una misma unidad topográfica, etc.

El estudio que abordamos sobre la industria lítica de los espacios analizados, constituye lo que podemos denominar un estudio tecnotipológico de mínimos. Este consiste en el análisis de una serie de aspectos básicos de carácter tecnológico y de carácter formal de los artefactos líticos. Para ello se utiliza una ficha en la que se recogen una serie de aspectos comunes (materia prima, alteraciones y dimensiones) a todos los artefactos y otros que son específicos y adaptados a la problemática de cada uno de los grupos tecnotipológicos más comunes de las colecciones (lascas simples, lascas retocadas, útiles sobre lasca, núcleos, bifaces, etc.).

\section{RESULTADOS DE LA «NUEVA ARQUEOLOGÍA» DEL PALEOLÍTICO}

El contexto en el que se han desarrollado nuestros trabajos coincide con dos de las zonas clásicas de estudio del paleolítico gallego: la cuenca media del Miño o Miño Ourensán y la sierra de Xistral (Figura 1). En uno y otro caso el pretexto ha sido la necesidad de tener que desarrollar en estas zonas diversos proyectos de Evaluación y Corrección de Impacto Arqueológico en Obras Públicas que fueron

Cuadernos de Estudios Gallegos, Tomo LI, Fascículo 117, Santiago 2004. (Págs. 133 - 151) 
encargados por diversas empresas al Laboratorio de Arqueología. Más concretamente, la primera zona fue investigada durante los trabajos de Control y Corrección de Impacto Arqueológico de dos obras de carácter lineal: la Autovía Rías Baixas y el Gasoducto de Transporte. El segundo se corresponde con el Plan É́lico Estratégico de Galicia y su impacto tiene un ámbito de tipo regional no existente en los proyectos anteriores.

\subsection{La ocupación paleolítica del Miño Ourensán}

La ocupación del paleolítico inferior y medio de la cuenca media del Miño o Miño Ourensán que aquí tratamos, se emplaza en una unidad morfológica característica del relieve de la Galicia interior, los «chaos» o superficies aplanadas (Pérez Alberti, 1986: 60-1). Para el estudio del paleolítico de este área hemos podido analizar dos transeptos emplazados al norte (Control y Corrección de la Gasificación de Galicia - Red de Ourense) y al sur del río Miño (tramo San Cibrao-Alto de Allariz de la autovía de las Rías Baixas), elemento regulador del paisaje de la zona.

Las analogías existentes desde el punto de vista geoarqueológico entre ambas, aconsejan hacer una exposición conjunta que facilite su análisis y comprensión.

La ocupación paleolítica del valle del Miño en su cuenca media, está caracterizada por la existencia de industrias líticas distribuidas de forma dispersa por el terreno. El registro arqueológico es espacialmente continuo aunque podemos establecer una serie de matices relacionados con la densidad variable con la que los artefactos se manifiestan a través del paisaje. Este está caracterizado por la monotonía del relieve debido a la existencia de grandes planicies (superficies de aplanamiento). Existen puntualmente colinas graníticas que han resistido la erosión. En consecuencia, las industrias líticas aparecen generalmente al aire libre, aunque en zonas donde la configuración litológica lo permite, hemos documentado la existencia de artefactos al abrigo de rocas.

Desde el punto de vista geoestratigráfico, esta característica configuración del relieve favorece la existencia de depósitos en cuya formación predominan las condiciones de sedimentación y transporte originadas por la acción fluvial, con preponderancia de materiales finos (limo-arcillosos) que, junto con la abundancia de agua, determinan que los terrenos permanezcan encharcados la mayor parte del año. En el caso de que los depósitos que contienen el material no hayan sido afectados por la acción antrópica reciente (desmontes derivados de actividades agrícolas, construcción de carreteras, acondicionamiento de solares y otros), los artefactos líticos aparecen siempre en la misma posición, asociados una facies erosiva posiblemente originada por una deforestación en el paisaje o por un recrudecimiento climático global en el medio (Costa, Blanco y Pérez, 1998: 18-20). 
Las consecuencias que debemos extraer desde un punto de vista arqueológico se concretan en un punto: los yacimientos analizados no son auténticos asentamientos arqueológicos, sino depósitos con materiales retrabajados procedentes de contextos anteriores y en los que las industrias aparecen removilizadas y procedentes del desmantelamiento de los niveles originales anteriores. Quiere esto decir que no se trata de yacimientos in situ o en posición primaria (López Cordeiro, 1998: 61). Hemos podido constatar en los últimos años como este extremo se puede hacer extensible a la mayor parte de las referencias clave del paleolítico inferior y medio gallego (Cerqueiro Landín, 1996: 71; Rodríguez Gracia, 1976: 30; Villar Quinteiro, 1996-7: 16).

En consecuencia de todo lo expuesto, debemos ser cautelosos a la hora de interpretar el registro arqueológico y, más concretamente, la naturaleza de las densidades de material más altas de las zonas de trabajo, ya que, en muchos casos, éstas pueden estar determinadas por la acción de agentes naturales o por la acción antrópica reciente, y no por haber constituido en el pasado lugares referenciales de poblamiento, es decir, áreas donde el asentamiento o actividad ha sido más estable (Domínguez-Rodrigo, 1996:18-9). Sólo cuando bajo condiciones locales muy concretas, la posición de las industrias y las características de los depósitos que las contienen, han permitido reconstruir de forma fehaciente el área de procedencia de una concentración sobresaliente de material, podemos referirnos a estos puntos como lugares referenciales.

Tanto al norte como al sur del Miño, hemos constatado una continuidad espacial más evidente en zonas amesetadas. Este es el caso de Os Montes de Rodeiro, emplazado al norte del Miño, y también de A Veiga-Campo da Mama, ubicado al sur. Con respecto a la industria lítica, ésta ha sido elaborada fundamentalmente sobre materias primas locales: cuarzo y cuarcita. Otras materias primas utilizadas son el sílex y el cristal de roca, aunque de forma marginal. El análisis de las alteraciones ha proporcionado altos porcentajes de piezas con acusados rasgos de rodamiento y oxidación. Con respecto a la distribución de piezas por grupos tecnotipológicos hay una clara hegemonía del grupo de lascas simples/restos de talla que supone siempre más del $65 \%$ del total. El resto de categorías representadas son: núcleos $(10 \%)$, útiles sobre lasca $(6 \%)$, lascas retocadas $(6 \%)$, bifaces $(3 \%)$, cantos trabajados $(2 \%)$, hendidores $(0,1 \%)$, lascas pré-determinadas $(0,1 \%)$ $\mathrm{y}$ otros $(6 \%)$. El estudio de la industria lítica por localidades nos ha permitido detectar diferencias significativas en las porcentajes y características de cada uno de los grupos tecnotipológicos que muy probablemente estén traduciendo diferencias de carácter temporal o funcional (diferentes estrategias de aprovechamiento del espacio) dentro de este extenso espacio. 


\subsection{La ocupación paleolítica de la sierra de Xistral}

La sierra de Xistral forma parte del conjunto serrano conocido como sierras septentrionales que marca la transición entre la Galicia interior y el litoral norte de Galicia (Figura 1). Este espacio es conocido desde hace más de tres décadas por albergar numerosos yacimientos encuadrables en momentos finales del paleolítico superior y epipaleolítico.

Los montes del Xistral forman la divisoria de aguas entre las cabeceras del Masma, Ouro, Moucide, Landro, etc. y las de Trimaz, Magdalena, Batón, Anllo, Ubedo o Miñotelo, tributarios del Miño. La zona de cumbres de la sierra llega a superar los 1.000 metros, concretamente el punto más alto es el Cuadramón con $1.056 \mathrm{~m}$. Podemos distinguir en Xistral dos niveles, uno superior que se extiende en torno a los $900 \mathrm{~m}$ de altitud y otro inferior a 800, con rastros claros de basculamiento. En la zona hay formaciones turbosas de gran interés que han contribuido en gran medida a reconstruir el paleoambiente de la zona desde hace unos 40.000 años. Desde el punto de vista litológico hay una gran variedad, de oeste a este encontramos esquistos, granitos, «ollo de sapo», pizarras, calizas, cuarcitas lo que ha favorecido un relieve contrastado sobre todo a medida que nos acercamos hacia el este donde el bandeado litológico es más frecuente. Esta variedad litológica unida a la tectónica, la acción fluvial y los cambios climáticos (entre los que destaca la morfogénesis glaciar) han jugado un papel muy importante en la configuración del relieve actual. Hay que destacar la importancia de las microformas graníticas que adquieren un gran desarrollo en el sector oriental de la sierra: rocas desnudas y lijadas por la erosión, «castelos», domos graníticos conviven con áreas lacustres en amplios alvéolos situados hacia el este, en las estribaciones del Cuadramón (Pérez Alberti, 1986: 26-28).

A finales de los años 90 tres empresas encargan al Laboratorio de Arqueología la tarea de evaluar el impacto arqueológico de la implantación del Plan Eólico Estratégico de Galicia en este espacio. La excepcionalidad de la zona desde el punto de vista arqueológico y ambiental, plantea como necesario el diseño de una estrategia integral de actuación que contribuya a compensar, en la medida de lo posible, el impacto que dicho Plan tiene sobre el patrimonio paleolítico. La ventaja que nos presentaba asumir un trabajo de estas características frente a los descritos en el apartado anterior, es que nos permitía adoptar una perspectiva regional ya que los parques eólicos se distribuyen por la totalidad de la sierra.

Las investigaciones en la sierra de Xistral siguen actualmente en curso por lo que los resultados que aquí se presentan se corresponden con el espacio donde se han intensificado los trabajos hasta el momento. Este espacio se localiza en el sector central de la sierra de Xistral ocupado por la línea de cumbres conformada 
por las alturas de los picos de Velilla Medroso (940 m.), Chao de Lamoso (1.045 m.), Cuadramón (1.056 m.) y Lombo Pequeno (1.028 m.). Al este de esta línea se extienden una serie de dorsales que van marcando la transición hacia los valles interiores, ocupados en este caso por las últimas estribaciones del macizo granítico de $A$ Toxiza, que configura un paisaje muy peculiar donde domos graníticos conviven con áreas lacustres en amplios alvéolos (Pérez Alberti, 1986: 26-8). La zona constituye el área de cabecera de los principales cursos de agua de la zona, el río Ouro y el Pedrido que en dirección SO-NE. atraviesan esta basta extensión hasta desembocar en aguas del Cantábrico. Desde el punto de vista litológico se suceden en una estrecha franja de terreno tres tipos de sustrato de oeste a este: cuarcitico, en la zona de cumbres, paragneis, en la zona media y granito en la banda más oriental. Las altitudes medias se sitúan entre los 1.056 metros del Alto de Cuadramón y los 700 de los terrenos inmediatos al río Pedrido.

La prospección superficial intensiva y de cobertura total (cuando ha sido posible) efectuada en la zona ha permitido confeccionar un mapa de distribución de industrias líticas en el que lejos de encontrar referencias aisladas en el paisaje (como se nos ponía de manifiesto en la bibliografía al uso), el registro vuelve a ser espacialmente continuo. Las únicas áreas en las que hasta el momento no hemos documentado industrias líticas son las cumbres más elevadas de la sierra, que se disponen entre los 900 y $1.000 \mathrm{~m}$. de altitud, pero a partir de la cota de $800 \mathrm{~m}$. se han documentado industrias en todo el espacio trabajado. Al igual que ocurría en el Miño Ourensán, la estructura de este registro puede ser descrita atendiendo a las diferentes densidades de artefactos, que en algunos casos han sido originadas por procesos de tipo natural, y en la mayoría exclusivamente antrópicas -las áreas con mayores densidades de artefactos se corresponderían con los lugares referenciales.

Las características de estos lugares referenciales y la forma en que la industria lítica se distribuye en el paisaje varían según el dominio litológico en el que nos situemos. El área ocupada por los gneises, caracterizada por la existencia de dorsales de cimas allanadas y vertientes de suave pendiente, manifiesta claramente un registro espacialmente continuo con predominio de densidades bajas de artefactos y densidades más altas de forma ocasional que rondan, como media las 30-40 piezas por metro cuadrado. Las industrias líticas recuperadas se caracterizan por los siguientes rasgos: (1) preferencia por las materias primas locales, es decir, el cuarzo y cuarcita en primer término y el cristal de roca, todos ellos fácilmente accesibles en las proximidades. Los materiales alóctonos como el sílex son marginales; (2) Hegemonia del soporte tipo lasca frente al soporte laminar cuyos porcentajes son ínfimos, extremo indudablemente determinado por las materias primas mayoritariamente utilizada; (3) Aprovechamiento diferencial de las materias 
primas, manifestado por ejemplo en la utilización del cristal de roca para la extracción laminar y elaboración de útiles sobre lasca. Los estudios geoarqueológicos realizados nos han permitido constatar que estos lugares referenciales no están en posición primaria. Sin embargo los procesos que han afectado a la industria lítica son aquellos derivados del lavado y encharcamiento del suelo, extremo que unido a una forma del relieve esencialmente plana y a los parámetros registrados en las orientaciones y buzamientos de las piezas, avalan la hipótesis de que la industria esté desplazada de forma muy leve o incluso que haya sido removilizada en el sitio donde originariamente fue depositada.

La ocupación del espacio en el área de dominio granítico responde a lo que podemos caracterizar como un sistema de apropiación territorial organizado en espacios circulares (Criado dir., 1991: 117). Si bien parece que el registro sigue siendo espacialmente continuo, las densidades son más bajas que en la zona no granítica y los puntos con industrias líticas se suelen concentrar en el entorno de las áreas de humedal de la zona (cuencas circo). Las diferencias vienen nuevamente determinadas por la existencia de sectores con densidades de material más altas que claramente se corresponderían con los lugares referenciales del territorio. Estos responden a unas mismas características: (1) abrigos rocosos que sin tener una altitud absoluta excesivamente dominante, constituyen hitos destacados en el paisaje, visibles desde diversos puntos de la sierra y entre los que existe una acusada intervisibilidad; (2) presentan una clara vinculación con zonas de tránsito o con áreas de captación de recursos (el control sobre estas zonas a veces no es inmediato pero disponen siempre de una amplia visibilidad zonal); (3) protegidos de los vientos dominantes por la existencia de al menos una roca en forma de visera; (4) tienen buenas condiciones de habitabilidad, al contar con zonas de allanada frente al abrigo que aparecen delimitadas por otras rocas del afloramiento conformando un espacio circular cerrado; (5) las densidades de material se triplican, al menos, respecto a las definidas para los espacios al aire libre.

\section{CONSECUENCIAS}

El PIPA del Laboratorio de Arqueología ha diseñado una estrategia de trabajo que, sin ser novedosa, (ya que ha sido ensayada con éxito en otros puntos de Europa desde hace unos veinticinco años), no había sido aplicada de forma sistemática en Galicia para estudiar el patrimonio paleolítico salvo muy contadas excepciones (Criado dir., 1991). Los trabajos efectuados nos presentan un registro perfectamente homologable al del resto de la península y Europa, aunque no exento de 
problemas. Nuestro objetivo ha sido iniciar una investigación analizando aquellos aspectos de este registro susceptibles de ser gestionados. Para ello hemos adoptado una perspectiva espacial que, a pesar de sus carencias, se manifiesta como una herramienta eficaz para comprender el aprovechamiento del paisaje y los modos de vida de las sociedades de cazadores-recolectores.

\section{BIBLIOGRAFÍA}

CERQUEIRO LANDÍN, D. 1996. As Gándaras de Budiño: Prehistoria e Historia». En «Os primeiros poboadores de Galicia: O Paleolitico». Cuadernos do Seminario de Sargadelos 73: 47-73. Edicións do Castro. A Coruña.

COSTA CASAIS, M.; BLANCO CHAO, R. y PÉREZ ALBERTI, A. 1998. Aplicaciones de la geomorfología al estudio de un yacimiento arqueológico. Gallaecia 17: 9-28.

CRIADO BOADO, F. (dir) 1991. Paisajes, Arqueología del Paisaje. El área Bocelo-Furelos entre los tiempos paleolíticos y medievales (campañas de 1987, 1988 y 1989). Arqueoloxía - Investigación 6. Santiago.

GRUPO DE ESTUDIOS PALEOAMBIENTALES. 1995. Valoración del Patrimonio natural e histórico de las sierras septentrionales de Galicia. Villalba.

LÓPEZ CORDEIRO, M. M. 1997. Aproximación a la problemática del paleolítico Inferior en Galicia: Estudio de la Cuenca Media del Miño. Trabajo de Investigación inédito.

LÓPEZ CORDEIRO, M. M. 1998. Aproximación a la problemática del paleolítico Inferior en Galicia: Estudio de la Cuenca Media del Miño. Gallaecia 17: 49-67.

LÓPEZ CORDEIRO, M. M. 2001. Estudio de depósitos con industrias líticas del Paleolítico Inferior y Medio en la cuenca media del Miño (Ourense). TAPA Traballos en Arqueoloxía da Paisaxe 24. LAFC-USC. Santiago.

LÓPEZ CORDEIRO, M. M. 2003. El yacimiento epipaleolítico de Chan da Cruz (Valadouro, Lugo): Síntesis de los primeros resultados» Complutum 14: 39-54. Madrid.

LÓPEZ CORDEIRO, M. M. 2002. La ocupación de espacios graníticos en la sierra de Xistral: el área arqueológica de Nordés (Valadouro, Lugo). Gallaecia 21: 61-86.

LÓPEZ CORDEIRO, M. M. 2003.La prospección en el paleolítico. Aplicaciones en el registro paleolítico gallego. Serie de Arqueología Espacial del Seminario de Arqueología y Etnología Turolense (e.p.)

PÉREZ ALBERTI, A. 1986. A Xeografia. O espacio xeográfico e o home. Vigo: Ed. Galaxia. A Coruña.

RAMIL REGO, E. y RAMIL SONEIRA, J. 1996. El fin de los tiempos glaciares en Galicia. En Os primeiros poboadores de Galicia: O Paleolitico (R. Fábregas Valcarce, ed.) Cuadernos do Seminario de Sargadelos 73: 117-46. Ediciós do Castro. Sada.

Cuadernos de Estudios Gallegos, Tomo LI, Fascículo 117, Santiago 2004. (Págs. 133 - 151) 
RODRÍGUEZ GRACIA, V. 1976. Notas sobre el yacimiento paleolítico de A Piteira, Toén (Orense). Boletin Auriense VI: 25-42.

SENÍN FERNÁNDEZ, I. J. 1995. A Investigación do paleolitico en Galicia. Revisión bibliográfica». Ediciós do Castro. Sada.

VILLAR QUINTEIRO, R. 1996-7. El yacimiento paleolítico de A Piteira (Toén) Ourense. Boletín Auriense XXVI: 9-26.



Figura 1.- Areas de trabajo en el contexto geográfico gallego.

Cuadernos de Estudios Gallegos, Tomo LI, Fascículo 117, Santiago 2004. (Págs. 133 - 151) 




Figura 2.- Traseptos norte y sur analizados en la cuenca media del Miño con áreas de dispersión de industrias líticas (sombreado). 


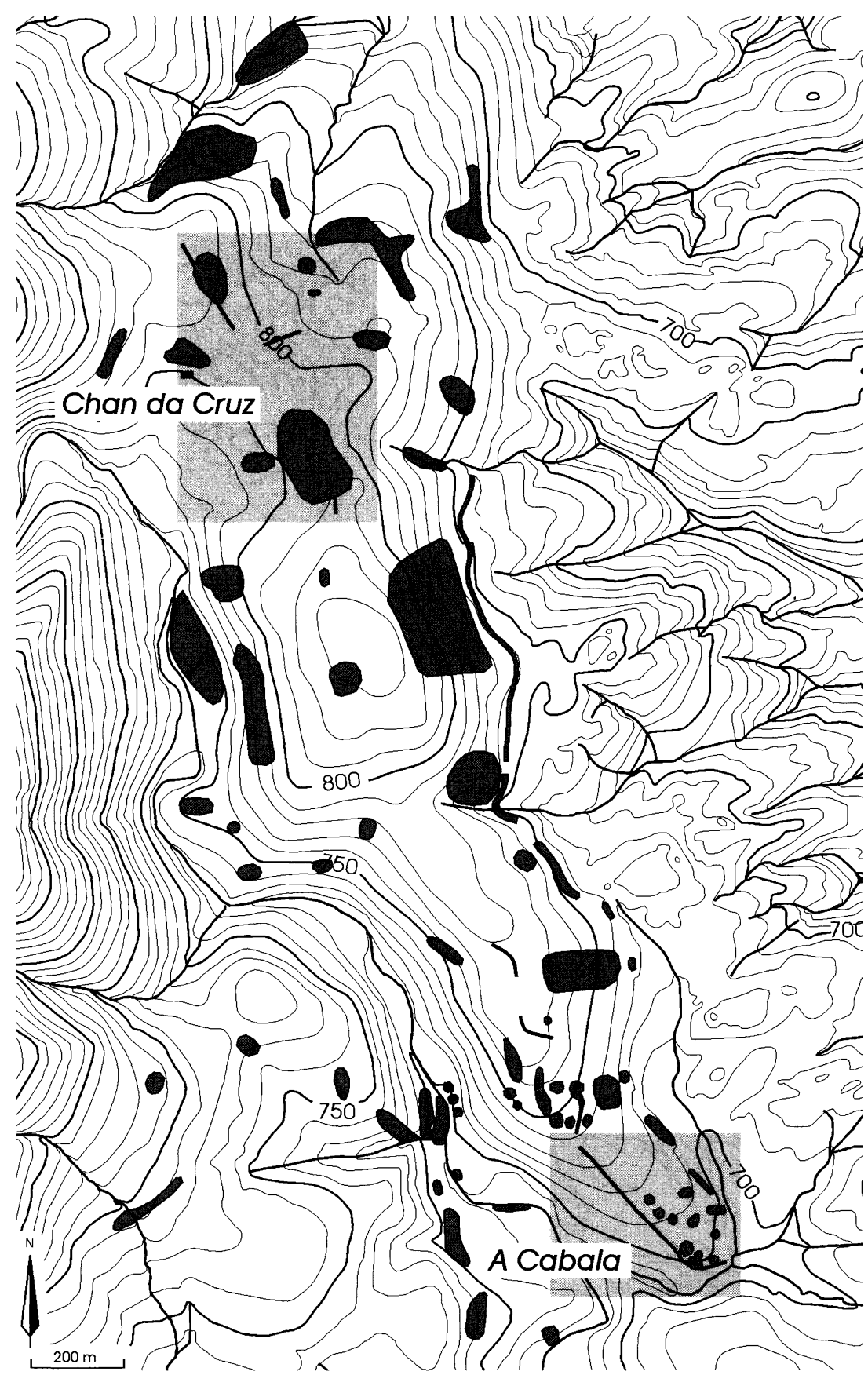

Figura 3.- Ocupación de espacios no graníticos en la sierra de Xistral (Alto da Cruz). 


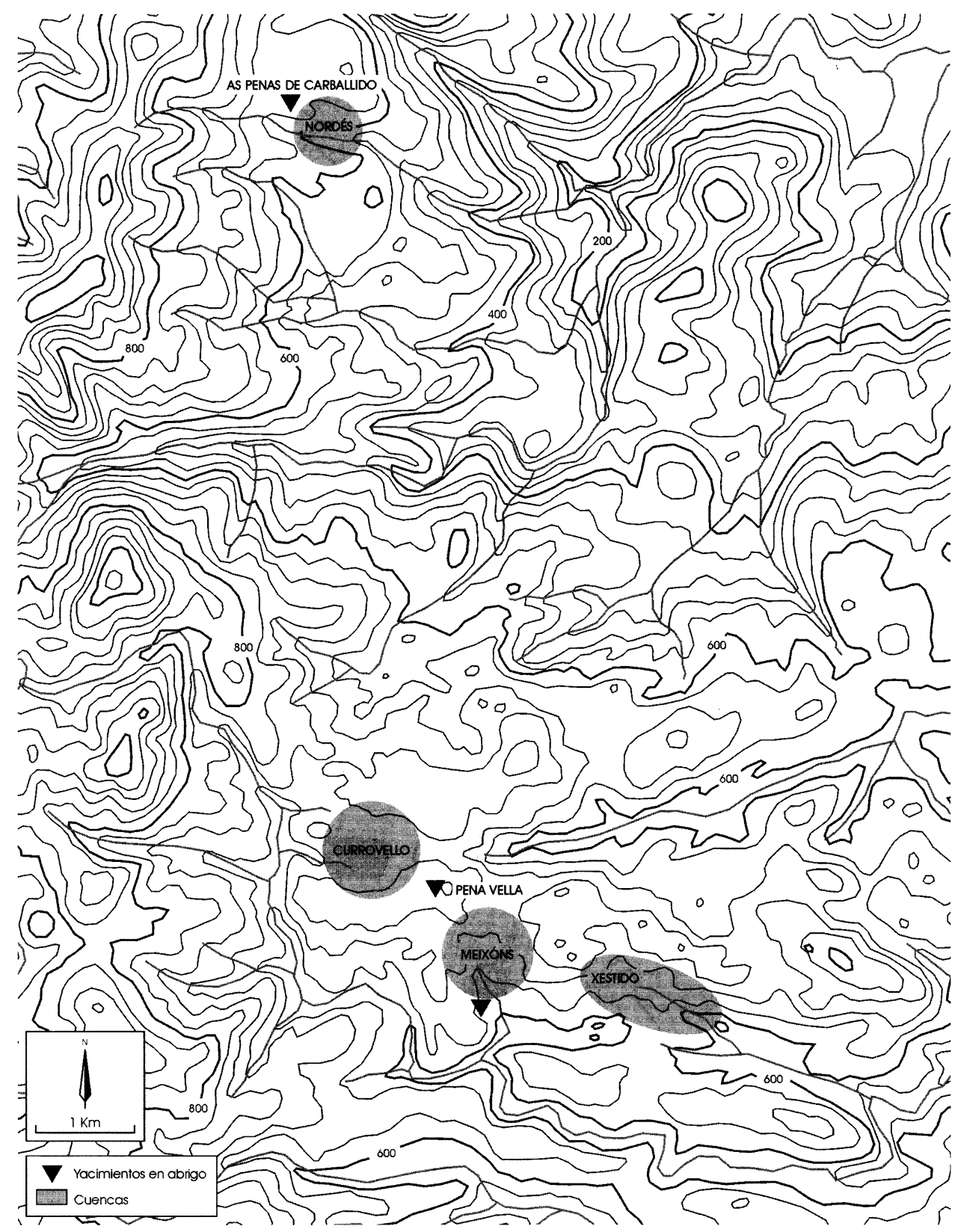

Figura 4.- Ocupación de espacios graníticos en la sierra de Xistral. 



Figura 5.- Industria lítica de la cuenca media del Miño (Montes de Rodeiro). 

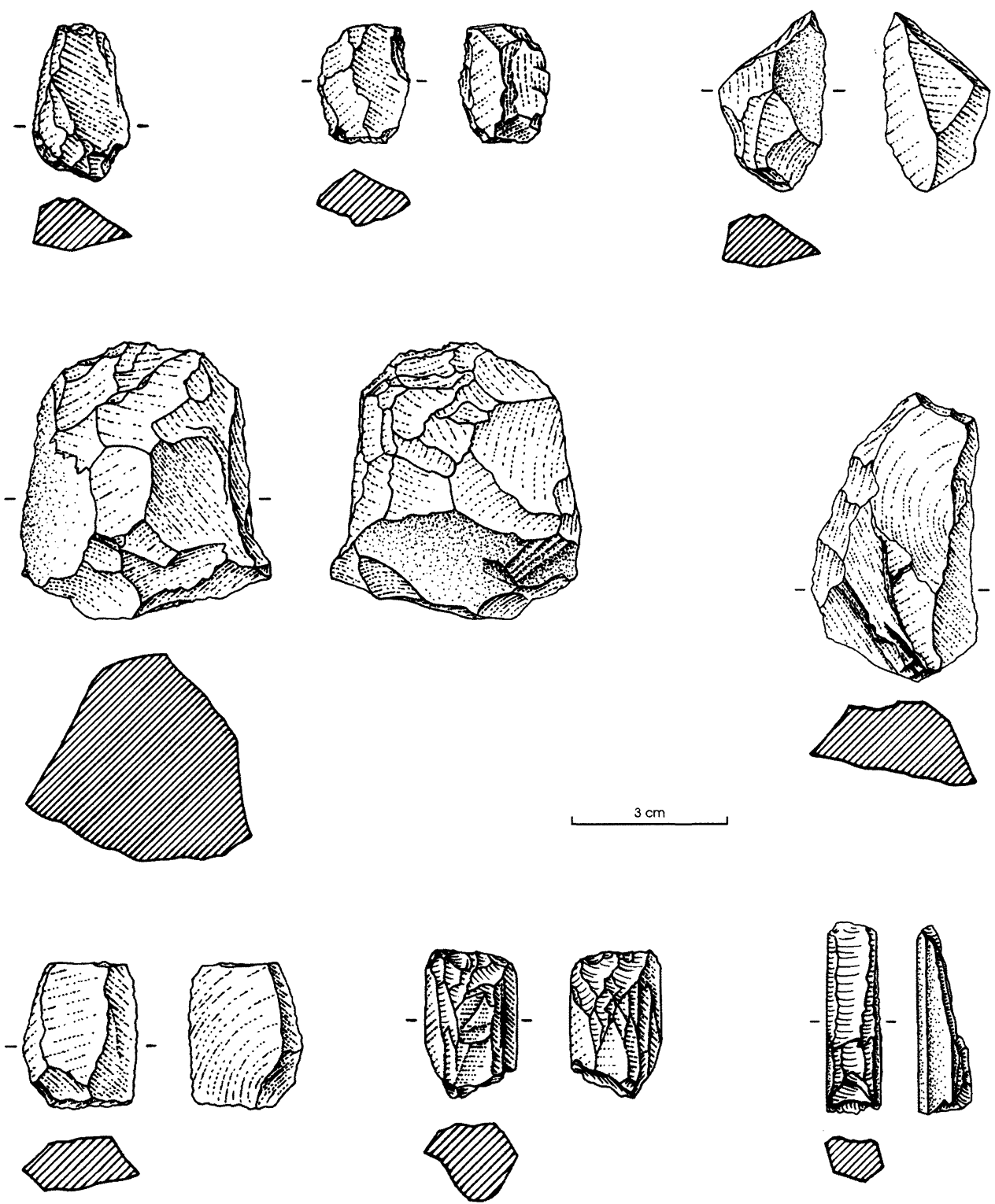

Figura 6.- Industria lítica de la sierra de Xistral (Chan da Cruz). 


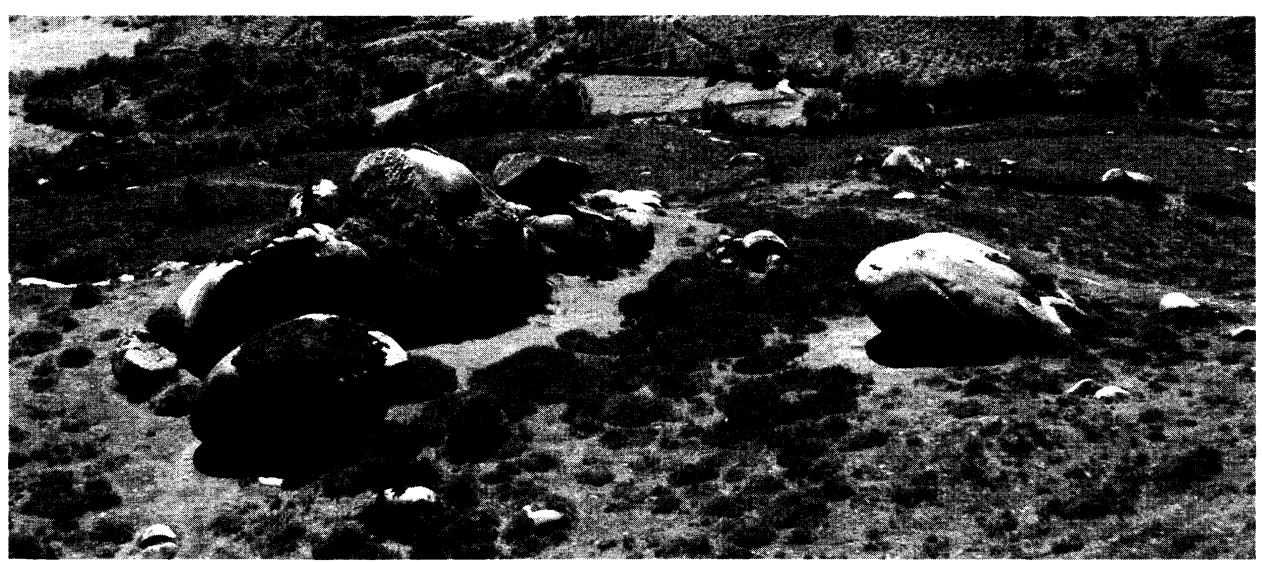

Figura 7.- Abrigo rocoso con configuración circular del espacio en el área de Xestido. 